\title{
Early postoperative bleeding impacts long-term survival following first-time on-pump coronary artery bypass grafting
}

\author{
Thomas Senage $^{1,2}$, Caroline Gerrard ${ }^{1}$, Narain Moorjani ${ }^{1}$, David P. Jenkins ${ }^{1}$, Jason M. Ali ${ }^{1}$ \\ ${ }^{1}$ Department of Cardiothoracic Surgery, Royal Papworth Hospital, Cambridge, UK; ${ }^{2}$ SPHERE (MethodS in Patient-Centred Outcomes and Health \\ Research), University of Nantes, Nantes, France \\ Contributions: (I) Conception and design: All authors; (II) Administrative support: C Gerrard, T Senage, JM Ali; (III) Provision of study materials \\ or patients: All authors; (IV) Collection and assembly of data: T Senage, C Gerrard, JM Ali; (V) Data analysis and interpretation: All authors; (VI) \\ Manuscript writing: All authors; (VII) Final approval of manuscript: All authors. \\ Correspondence to: Jason M. Ali, PhD. Department of Cardiothoracic Surgery, Royal Papworth Hospital, Cambridge CB20AY, UK. \\ Email: ja297@cam.ac.uk.
}

\begin{abstract}
Background: Significant bleeding following cardiac surgery is a recognised complication, associated with a requirement for re-exploration and blood transfusion, both associated with increased morbidity and early mortality. The aim of this study was to examine the impact of the volume of early postoperative bleeding on long-term survival for patients undergoing coronary artery bypass grafting (CABG).

Methods: A retrospective analysis was performed of patients undergoing first-time isolated CABG at a single centre between January 2003 and April 2013, conditional from 30-day survival.

Results: Six thousand two hundred and sixty-five patients were analysed, with a mean Logistic EuroSCORE of $4.9 \%$. The mean age was 67.8 years. Median follow-up was 11.5 years. The overall 10 - and 15 -year survival was $70.6 \%$ and $51.9 \%$ respectively. Following surgery, $4.6 \%(n=291)$ required return to theatre for re-exploration, and $43.6 \%(n=2,733)$ received at least one red cell transfusion. In multivariable analysis, the strongest correlates of mortality were age, smoking history, BMI, COPD, renal impairment, preoperative left ventricular function and preoperative haemoglobin $(\mathrm{Hb})$ level. Twelve-hour blood loss was an additional predictor of inferior longterm survival. Five-year survival was $89.6 \%$ for patients with $<500 \mathrm{~mL}$ blood loss, $86.8 \%$ for $500-1,000 \mathrm{~mL}$ and $83.8 \%$ for $>1,000 \mathrm{~mL}$. Re-exploration and receiving blood transfusion were not associated with reduced long-term survival.
\end{abstract}

Conclusions: Significant 12-hour blood loss is associated with inferior long-term survival following CABG. This observation supports efforts aimed at improving intra-operative haemostasis and aggressive management of patients with early signs of bleeding.

Keywords: Bleeding; re-exploration; outcomes; coronary artery bypass grafting (CABG)

Submitted Jul 29, 2021. Accepted for publication Sep 27, 2021.

doi: $10.21037 /$ jtd-21-1241

View this article at: https://dx.doi.org/10.21037/jtd-21-1241

\section{Introduction}

Although there are many strategies employed with the aim of reducing postoperative bleeding after cardiac surgery, such as intraoperative haemostasis checklists (1) and point of care monitoring of coagulation status (2), bleeding remains an important complication.

Significant postoperative bleeding is associated with re-exploration and blood transfusion, both associated with inferior outcomes $(3,4)$. A recent review concluded that patients who bleed significantly and undergo reexploration have increased mortality and experience greater morbidity (5). Similarly, studies have demonstrated an association between blood transfusion and increases in short- and long-term mortality, with a correlation between 
the amount of blood transfused and morbidity $(6,7)$. These studies have driven a shift from more liberal use of blood products to a more restrictive and goal-directed approach.

There is also evidence that bleeding itself is harmful, independently of re-exploration and significant blood transfusion, with studies demonstrating association with increased postoperative mortality risk (8-11). To date though, there is little evidence exploring the impact of significant bleeding on longer term survival.

The aim of our study was to examine the impact of early postoperative bleeding volume on long-term survival for patients undergoing coronary artery bypass grafting (CABG).

We present the following article in accordance with the STROBE reporting checklist (available at https://dx.doi. org/10.21037/jtd-21-1241).

\section{Methods}

\section{Patient population}

The study was conducted in accordance with the Declaration of Helsinki (as revised in 2013). The study was approved by the Royal Papworth Hospital Clinical Governance Department and individual consent for this retrospective analysis was waived. This was a retrospective observational study conducted at a single institution. All patients undergoing CABG at Royal Papworth Hospital between January 2003 and April 2013 were included. Demographic, intra-operative and post-operative outcome data were collected prospectively, and a full dataset was available for every patient. Mortality information was obtained from the UK National Health Service patient administration system and was therefore available for all patients included in the study. The hospital Clinical Research Ethics Committee provided approval for the study.

\section{Patient exclusion}

The following patients were excluded from analysis due to there being small numbers in each group:

* Previous cardiac surgery.

* Single coronary artery bypass graft.

* Minimally invasive direct CABG.

* Off-pump CABG.

* End-stage renal failure undergoing haemodialysis.

In this series there were few patients who underwent single coronary bypass grafting, many of whom underwent hybrid revascularisation. They represent a different group of patients from the majority of our practice, hence their exclusion.

The aim was to assess the impact of postoperative blood loss on long-term survival independent of severe postoperative complications, and therefore patients who died within the first 30-day following surgery (considered perioperative mortality) were also excluded from the analysis.

\section{Patient management}

The operating techniques and mode of myocardial preservation were left to the 16 operating surgeon's discretion. A common surgical approach via median sternotomy with extracorporeal bypass was adopted, with proximal anastomoses performed after cross-clamp release. For elective patients during this era, anti-platelet and anticoagulant medications were discontinued in advance of admission: aspirin 5-day, clopidogrel 7-day and warfarin 5 -day. For urgent and emergency operations aspirin was continued until surgery whilst clopidogrel was discontinued once the prospect of surgery was identified.

The decision to re-explore patients was at the operating surgeon's discretion. During the era of this study the unit policy was a transfusion trigger of $80 \mathrm{~g} / \mathrm{L}$.

\section{Study endpoint}

The primary outcome measure was long-term survival. The impact of postoperative bleeding on survival was examined, defining significant bleeding on the basis of:

* Mediastinal drainage within the first 12 hours, as a categorical variable: $<500 \mathrm{~mL}$, between 500 and $1,000 \mathrm{~mL}$, and $>1,000 \mathrm{~mL}$.

* Requirement for re-exploration for suspected bleeding within the first 48 hours.

- Red blood cell transfusion, as a categorical variable: none, $<2$ units, and $>2$ units (including intraoperative and post-operative period).

For the blood loss continuous variable, the log-linearity assumption was not confirmed (checked by using the quartiles of the variable). Therefore, a transformation of the variable in a categorical variable was performed. The 500 and 1,000 thresholds were chosen following clinical judgment. 


\section{Statistical analysis}

Statistical analysis was performed using R 2.15.0 (R Core Team, Vienna, Austria). Quantitative data are expressed as mean \pm standard deviation, while categorical variables are expressed as a frequency. For comparison, continuous variables were analysed with the Mann-Whitney $U$ test if not normally distributed and with the students $t$-test (or one-way ANOVA test) if normally distributed. categorical variables were analysed with the Chi-squared test. A P value $\leq 0.05$ was considered statistically significant.

The main outcome of this study was the time between surgery and patient death. A first selection of covariates was performed with the use of the, including covariates associated with the blood loss variable $(\mathrm{P}<0.20)$ and/or the main outcome (Kaplan-Meier estimator and log-rank test, $\mathrm{P}<0.20)$. Continuous covariates have been transformed if the log-linearity assumption was not confirmed (checked by using the quartiles of the covariate).

The following perioperative data were considered as possible correlates of death: operative age (years), sex, body mass index (BMI), family history, high blood pressure history, diabetes mellitus, smoking history, dyslipidaemia, obesity, chronic obstructive pulmonary disease (COPD), preoperative creatinine clearance, left ventricular function, surgery priority, preoperative haemoglobin $(\mathrm{Hb})$, cardiopulmonary bypass (CPB) time, cross clamping time, number of grafts, type of grafts, final $\mathrm{Hb}$ in theatre, re-exploration for bleeding in the first 48 hours, blood transfusion, and, finally, blood loss in the first 12 hours.

For the multivariable analysis, a Cox proportional hazards regression model have been performed. Age and blood loss have been forced into the model. Hazards proportionality was checked graphically by plotting log-minus-log survival curves and by testing the scaled Schoenfeld residuals, and no violation was observed. A backward elimination was performed, manually variable by variable. This procedure allowed us the identification of possible confounding factors (variation of blood loss regression coefficient of $>20 \%$ ).

\section{Results}

\section{Patient population}

Over the period of study 16,109 patients underwent surgery, of whom 7,927 patients underwent CABG. Of these, 6,265 patients met inclusion criteria. The 30-day mortality of this cohort was $1.2 \%(n=72)$, leaving a final cohort of 6,265 who had 30-day conditional survival. The preoperative characteristics of these patients are detailed in Table 1. The mean age was 67.8 ( $\mathrm{SD}=9.4)$ years. Cardiovascular risk factors were prevalent: $71.9 \%(n=4,112)$ with smoking history, $75.5 \%(\mathrm{n}=4,678)$ with hypertension, $32.8 \%$ with obesity $(\mathrm{n}=2,009)$, and $24.8 \%(\mathrm{n}=1,557)$ with diabetes. In $77.8 \%(\mathrm{n}=4,876)$ surgery was performed electively. The mean Logistic EuroSCORE was $4.9 \%$ ( $\mathrm{SD}=6.2$, range, $0.88-80.25)$.

\section{Operative characteristics}

Details of the surgery are summarised in Table 2. The majority had three or more bypass grafts $(85.8 \% \mathrm{n}=5,811)$, with the majority using the left internal mammary artery (LIMA) and saphenous vein graft (SVG) $(85.2 \%, \mathrm{n}=5,340)$. The radial artery was harvested in $5.3 \%(\mathrm{n}=331)$ of patients and only $1.5 \%(n=96)$ had bilateral internal mammary arteries harvested. The mean cross clamp and bypass times were respectively 46 and 82 minutes.

\section{Bleeding and patient outcomes}

Bleeding outcomes are summarised in Table 2. Following surgery, $4.6 \%(n=291)$ required re-exploration, and $43.6 \%$ $(n=2,733)$ received at least one red cell transfusion. Blood loss within the first 12 hours was $<500 \mathrm{~mL}$ in $71.2 \%$ $(\mathrm{n}=4,462)$ of patients, between 500 and $1,000 \mathrm{~mL}$ in $22.4 \%$ $(\mathrm{n}=1,403)$ and $>1,000 \mathrm{~mL}$ in $6.4 \%(\mathrm{n}=400)$ (Figure 1).

The median follow-up was 11.5 years (ranging from 0.1 to 16.0 ) after surgery. There were 2,139 deaths during follow-up (34.1\%). The 10 - and 15 -year survival rates were $70.6 \%$ and $51.9 \%$ respectively.

\section{Long term survival}

The multivariable Cox model for mortality is shown in Table 3. Concordance of the final multivariable model $=0.683$ (se $=0.007)$. The preoperative and patient variables found to be independently correlated with inferior survival were: age, smoking history, BMI, chronic pulmonary disease (CPD), diabetes, creatinine clearance, left ventricular ejection fraction, and preoperative $\mathrm{Hb}$ level.

Twelve-hour blood loss was found to be associated with an increased risk of long-term mortality if the blood loss was $>500 \mathrm{~mL}(\mathrm{P}=0.025)$ and $>1,000 \mathrm{~mL}(\mathrm{P}=0.001)$. Re-exploration and receiving blood transfusion were not independent predictors of long-term survival. Volume of bleeding was retained as an independent predictor even 
Table 1 Patient demographic data—correlates of long-term survival: univariable analysis

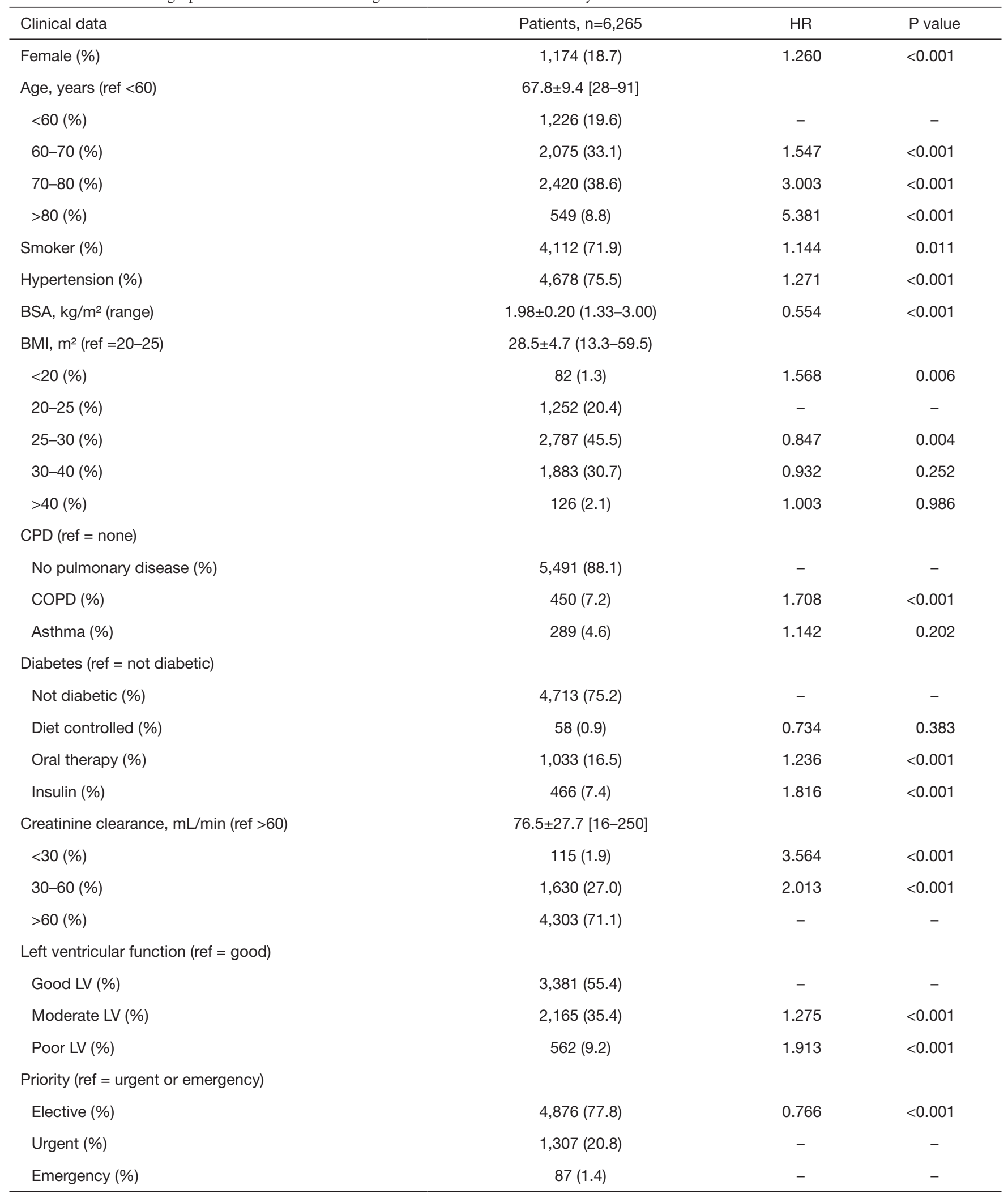

Table 1 (continued) 
Table 1 (continued)

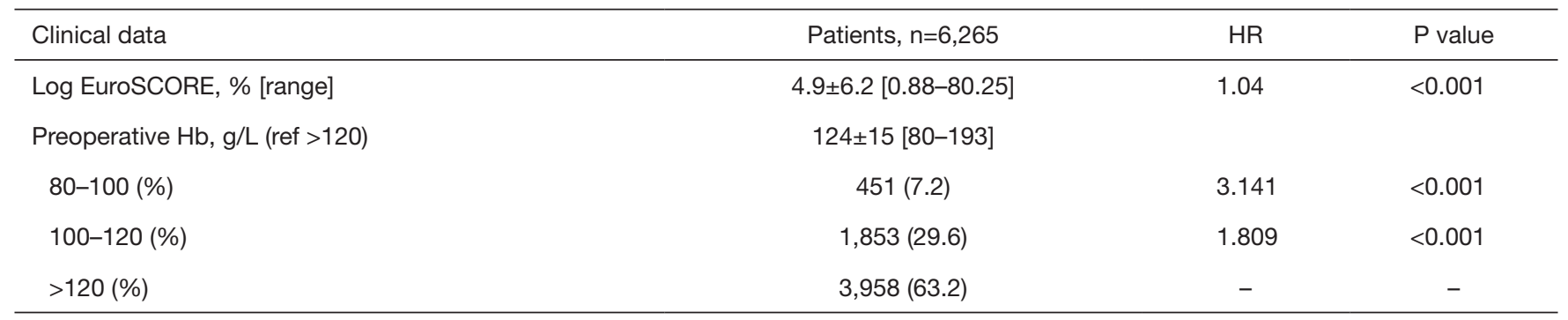

Percentages quoted are for the patients with data available for that particular variable. BMI, body mass index; CPD, chronic pulmonary disease; COPD, chronic obstructive pulmonary disease; LV, left ventricle; Hb, haemoglobin.

Table 2 Patient surgical data—correlates of long-term survival: univariable analysis

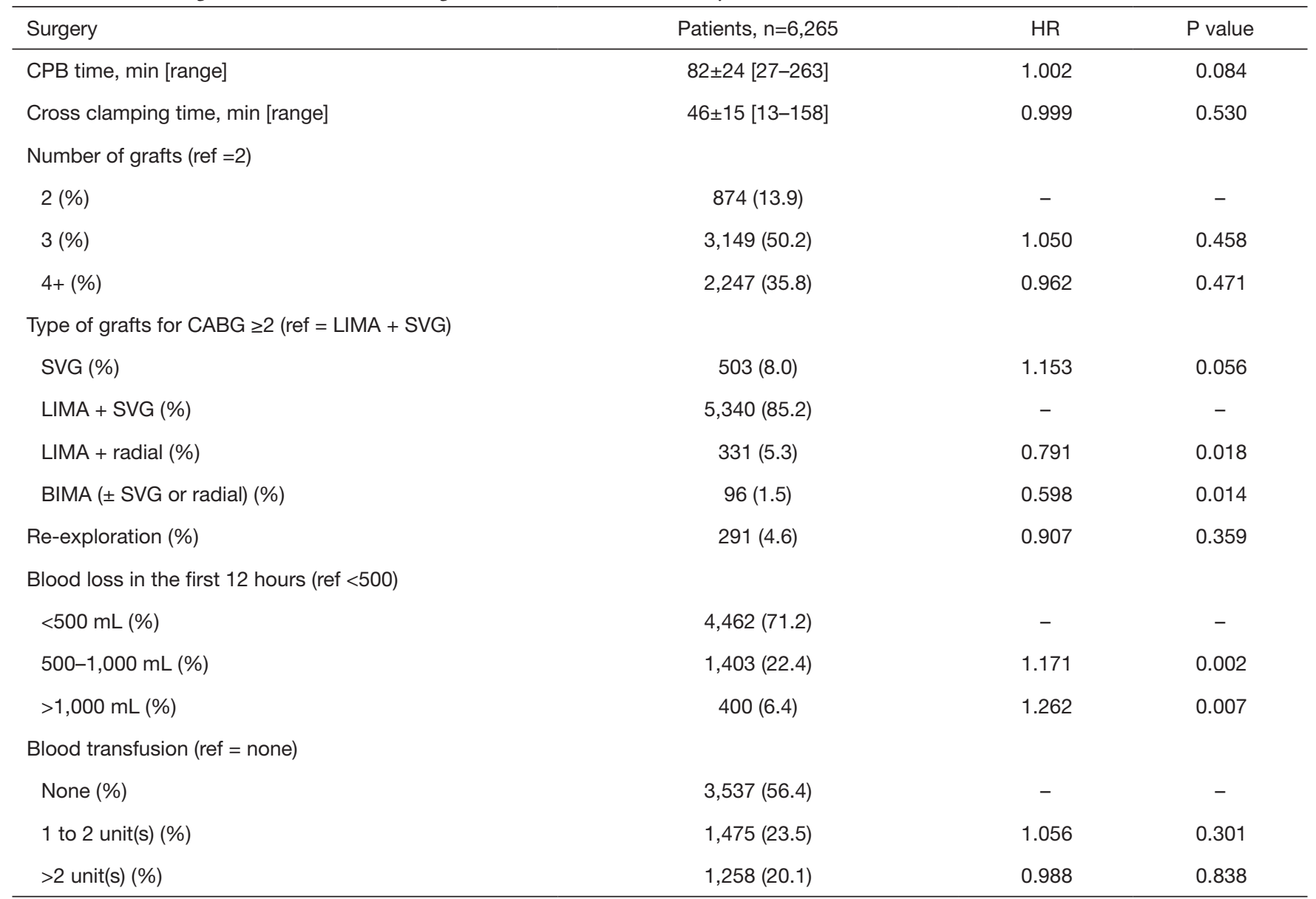

Percentages quoted are for the patients with data available for that particular variable. CPB, cardiopulmonary bypass; CABG, coronary artery bypass grafting; SVG, saphenous vein graft; LIMA, left internal mammary artery; BIMA, bilateral internal mammary artery. 


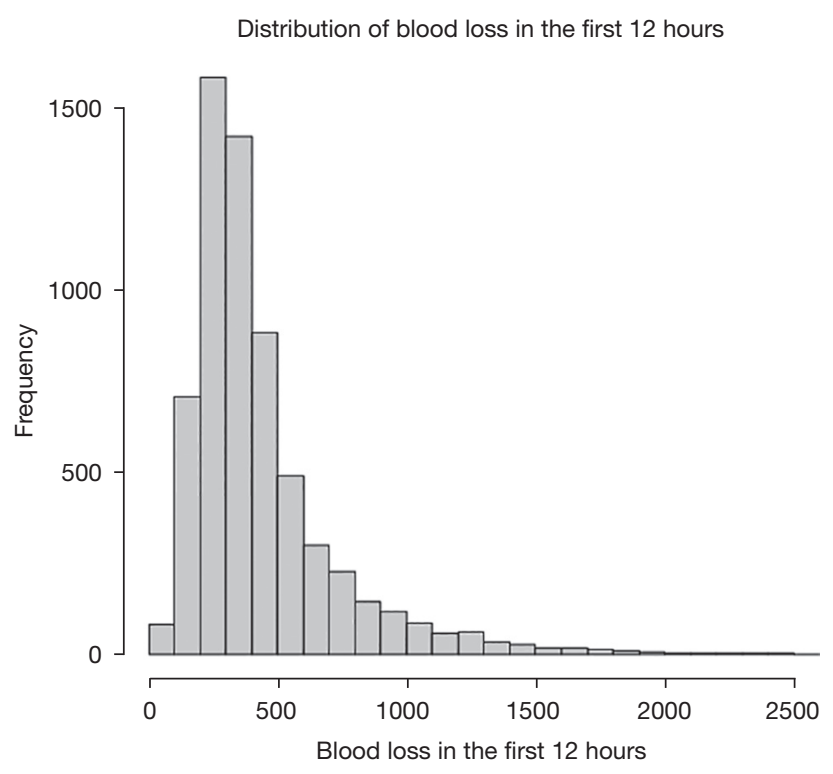

Figure 1 Histogram showing the incidence and volume of 12-hour blood loss.

Table 3 Multivariable Cox model analysis of long-term survival

\begin{tabular}{|c|c|c|}
\hline Clinical data & $\mathrm{HR}(95 \% \mathrm{Cl})$ & $P$ value \\
\hline \multicolumn{3}{|l|}{ Age, years (ref <60) } \\
\hline$<60$ & - & - \\
\hline $60-70$ & $1.479(1.247-1.753)$ & $<0.001$ \\
\hline $70-80$ & $2.567(2.174-3.033)$ & $<0.001$ \\
\hline$>80$ & $3.760(3.044-4.645)$ & $<0.001$ \\
\hline Smoker & $1.199(1.076-1.336)$ & 0.001 \\
\hline \multicolumn{3}{|l|}{ BMI, m² (ref =20-25) } \\
\hline$<20$ & $1.106(0.783-1.563)$ & 0.568 \\
\hline $20-25$ & - & - \\
\hline $25-30$ & $1.021(0.901-1.156)$ & 0.744 \\
\hline $30-40$ & $1.209(1.053-1.388)$ & 0.007 \\
\hline$>40$ & $1.773(1.262-2.490)$ & 0.001 \\
\hline \multicolumn{3}{|c|}{ CPD (ref = no pulmonary disease) } \\
\hline No pulmonary disease & - & - \\
\hline COPD & $1.432(1.222-1.676)$ & $<0.001$ \\
\hline Asthma & $1.044(0.840-1.299)$ & 0.694 \\
\hline
\end{tabular}

Table 3 (continued)
Table 3 (continued)

\begin{tabular}{|c|c|c|}
\hline Clinical data & $\mathrm{HR}(95 \% \mathrm{Cl})$ & $P$ value \\
\hline \multicolumn{3}{|c|}{ Diabetes (ref $=$ not diabetic) } \\
\hline Not diabetic & - & - \\
\hline Diet controlled & $0.658(0.328-1.321)$ & 0.239 \\
\hline Oral therapy & $1.138(1.007-1.285)$ & 0.039 \\
\hline Insulin & $1.544(1.317-1.810)$ & $<0.001$ \\
\hline \multicolumn{3}{|c|}{ Creatinine clearance, $\mathrm{mL} / \mathrm{min}($ ref $>60)$} \\
\hline$<30$ & $1.351(1.009-1.808)$ & 0.043 \\
\hline $30-60$ & $1.177(1.047-1.323)$ & 0.006 \\
\hline$>60$ & - & - \\
\hline \multicolumn{3}{|c|}{ Left ventricular function (ref = good LV) } \\
\hline Good LV & - & - \\
\hline Moderate LV & $1.176(1.062-1.301)$ & 0.002 \\
\hline Poor LV & $1.593(1.376-1.844)$ & $<0.001$ \\
\hline \multicolumn{3}{|c|}{ Preoperative $\mathrm{Hb}, \mathrm{g} / \mathrm{L}($ ref $>120)$} \\
\hline $80-100$ & $2.181(1.864-2.552)$ & $<0.001$ \\
\hline $100-120$ & $1.384(1.245-1.538)$ & $<0.001$ \\
\hline$>120$ & - & - \\
\hline \multicolumn{3}{|c|}{ Blood loss in the first 12 hours (ref $<500$ ) } \\
\hline$<500 \mathrm{~mL}$ & - & - \\
\hline $500-1,000 \mathrm{~mL}$ & $1.134(1.016-1.265)$ & 0.025 \\
\hline$>1,000 \mathrm{~mL}$ & $1.339(1.118-1.602)$ & 0.001 \\
\hline
\end{tabular}

when conditional survival was extended to 1 -year. The same results were seen for the entire cohort including those patients who died within 30 days (Figure S1).

\section{Blood loss within the first 12 hours}

Table 4 presents the patient characteristics divided by blood loss category. More significant bleeding was associated with male gender, increasing age, operative urgency and increasing logistic EuroSCORE. Patients going on to bleed had a lower $\mathrm{Hb}$ on arrival in the ICU. There was no association between 12-hour blood loss and the incidence of 
Table 4 Cohort characteristics according to the first 12-hour blood loss

\begin{tabular}{|c|c|c|c|c|}
\hline Clinical data & \multicolumn{3}{|c|}{ Blood loss in the first 12 hours } & $P$ value \\
\hline Female (\%) & $908(20.3)$ & $206(14.7)$ & $59(14.7)$ & $<0.001$ \\
\hline Age, years & $67.5 \pm 9.4[28-91]$ & $68.6 \pm 9.5[38-89]$ & $68.6 \pm 9.1[39-89]$ & 0.001 \\
\hline$<60(\%)$ & $906(20.3)$ & $247(17.6)$ & $71(17.8)$ & \\
\hline $70-80(\%)$ & $1,668(37.4)$ & $581(41.4)$ & $171(42.7)$ & \\
\hline$>80(\%)$ & $368(8.2)$ & $147(10.5)$ & $34(8.5)$ & \\
\hline Smoker (\%) & $2,971(72.6)$ & $876(69.1)$ & $261(72.3)$ & 0.052 \\
\hline Hypertension (\%) & $3,339(75.7)$ & $1,050(75.6)$ & $286(72.6)$ & 0.391 \\
\hline$<20(\%)$ & $49(1.1)$ & $23(1.7)$ & $10(2.5)$ & \\
\hline 20-25 (\%) & $832(19.1)$ & $328(24.0)$ & $91(23.1)$ & \\
\hline $25-30(\%)$ & $1,967(45.1)$ & $629(46.0)$ & $188(47.7)$ & \\
\hline 30-40 (\%) & $1,415(32.4)$ & $371(27.2)$ & $96(24.4)$ & \\
\hline$>40(\%)$ & $102(2.3)$ & $15(1.1)$ & $9(2.3)$ & \\
\hline CPD & & & & 0.732 \\
\hline No disease (\%) & $3,904(87.9)$ & $1,227(88.3)$ & $356(89.7)$ & \\
\hline COPD (\%) & $320(7.2)$ & $102(7.3)$ & $27(6.8)$ & \\
\hline Insulin (\%) & $348(7.8)$ & $91(6.5)$ & $27(6.7)$ & \\
\hline Creatinine clearance, $\mathrm{mL} / \mathrm{min}$ & $77.2 \pm 27.6[17-250]$ & $74.7 \pm 27.5[16-197]$ & $74.9 \pm 28.2[17-211]$ & 0.237 \\
\hline$<30(\%)$ & $78(1.8)$ & $29(2.1)$ & $8(2.1)$ & \\
\hline $30-60(\%)$ & 1,125 (26.2) & $395(29.1)$ & $109(27.9)$ & \\
\hline$>60(\%)$ & $3,092(72.0)$ & $934(68.8)$ & $273(70.0)$ & \\
\hline Left ventricular function & & & & 0.450 \\
\hline Good (\%) & $2,421(55.8)$ & $729(53.3)$ & $228(57.7)$ & \\
\hline Moderate (\%) & $1,526(35.2)$ & $507(37.1)$ & $131(33.2)$ & \\
\hline Poor (\%) & $393(9.1)$ & $132(9.6)$ & $36(9.1)$ & \\
\hline
\end{tabular}

Table 4 (continued) 
Table 4 (continued)

\begin{tabular}{|c|c|c|c|c|}
\hline Clinical data & \multicolumn{3}{|c|}{ Blood loss in the first 12 hours } & $P$ value \\
\hline Priority & & & & $<0.001$ \\
\hline Elective (\%) & 3,537 (79.3) & $1,072(76.4)$ & $264(66.0)$ & \\
\hline Urgent (\%) & $873(19.6)$ & $309(22.0)$ & $123(30.8)$ & \\
\hline Log EuroSCORE, \% (range) & $4.7 \pm 6.2[0.88-80.25]$ & $5.1 \pm 6.3[0.88-62.2]$ & $5.6 \pm 6.6[0.88-45.6]$ & 0.008 \\
\hline Preop Hb, g/L & $124 \pm 15[80-193]$ & $123 \pm 15[80-178]$ & $122 \pm 16[80-166]$ & 0.115 \\
\hline $80-100(\%)$ & $298(6.7)$ & $113(8.1)$ & $39(9.8)$ & \\
\hline $100-120(\%)$ & $1,328(29.8)$ & $406(29.0)$ & $115(28.9)$ & \\
\hline \multicolumn{5}{|l|}{ Surgery } \\
\hline CPB time, min [range] & $81 \pm 24[27-263]$ & $83 \pm 24[27-180]$ & $84 \pm 27[28-228]$ & 0.031 \\
\hline $\begin{array}{l}\text { Cross clamping time, min } \\
\text { [range] }\end{array}$ & $46 \pm 15[13-158]$ & $46 \pm 15[15-126]$ & $47 \pm 16[15-158]$ & 0.538 \\
\hline Number of grafts & & & & 0.003 \\
\hline $2(\%)$ & $657(14.7)$ & $164(11.7)$ & $53(13.3)$ & \\
\hline $3(\%)$ & $2,254(50.5)$ & $715(51.0)$ & $179(44.7)$ & \\
\hline $4+(\%)$ & $1,551(34.8)$ & $524(37.3)$ & $168(42.0)$ & \\
\hline Type of grafts for $C A B G \geq 2$ & & & & 0.001 \\
\hline$<80(\%)$ & $394(9.3)$ & $163(12.1)$ & $52(13.6)$ & \\
\hline $80-100(\%)$ & $2,224(52.7)$ & $726(53.9)$ & $212(55.4)$ & \\
\hline $100-120(\%)$ & $1,413(33.5)$ & $400(29.7)$ & $106(27.7)$ & \\
\hline >120 (\%) & $188(4.5)$ & $59(4.4)$ & $13(3.4)$ & \\
\hline Re-exploration <48 h (\%) & $205(4.6)$ & $63(4.5)$ & $23(5.7)$ & 0.548 \\
\hline Blood transfusion & & & & 0.241 \\
\hline None (\%) & $2,554(57.2)$ & $773(55.1)$ & $208(52.0)$ & \\
\hline 1 to 2 unit(s) (\%) & $1,029(23.1)$ & $342(24.4)$ & $102(25.5)$ & \\
\hline >2 unit(s) (\%) & $879(19.7)$ & $288(20.5)$ & $90(22.5)$ & \\
\hline No blood transfusion (\%) & $2,554(57.2)$ & $773(55.1)$ & $208(52.0)$ & 0.067 \\
\hline
\end{tabular}

Percentages quoted are for the patients with data available for that particular variable. BSA, body surface area; BMI, body mass index; CPD, chronic pulmonary disease; COPD, chronic obstructive pulmonary disease; $\mathrm{Hb}$, haemoglobin; CPB, cardiopulmonary bypass; CABG, coronary artery bypass grafting; SVG, saphenous vein graft; LIMA, left internal mammary artery; BIMA, bilateral internal mammary artery. 


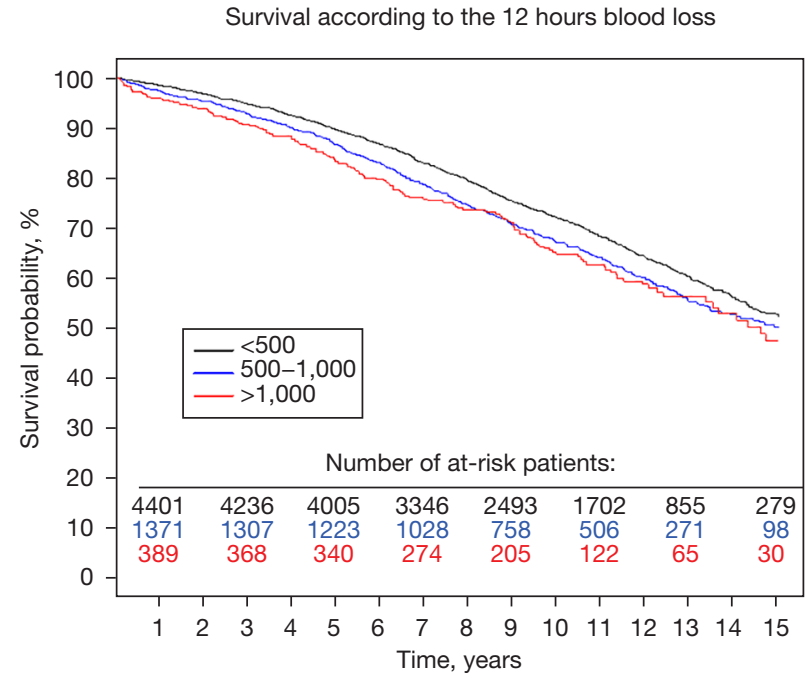

Figure 2 Impact of postoperative bleeding on long term survival for patients with 30-day conditional survival.

re-exploration or the administration of blood transfusions, although there was a trend-and this may reflect the absence of guidelines protocolising these and the different thresholds of individual surgeons to re-explore.

The impact of bleeding on long-term survival is demonstrated in Figure 2. The 5-year survival rates for postoperative blood loss $<500 \mathrm{~mL}$, between 500 and 1,000 , and $>1,000 \mathrm{~mL}$ respectively, were: $89.6 \%$, $86.8 \%$ and $72.2 \%$, and 10 -year survival rates $83.8 \%, 67.2 \%$ and $65.1 \%$. The impact of receiving blood transfusion on long-term survival was also explored. There were no significant differences in the long-term survival comparing those who received or did not receive transfusion, respectively $\mathrm{HR}=1.04$ [95\% confidence interval (CI), 0.87 1.23 ] and 0.98 (95\% CI, $0.72-1.35)$ in the $>500$ and $>1,000$ $\mathrm{mL}$ bleeding groups (Figure 3).

\section{Outcomes following aortic valve replacement (AVR)}

To examine if this observation was unique to the CABG population, we repeated the analysis for the 3,689 patients who underwent isolated AVR during the same period (Table S1). Blood loss 500-1,000 and $>1,000 \mathrm{~mL}$ were both significant on univariable analysis $(\mathrm{P}<0.001)$ as being predictors of long-term survival. However, on multivariable analysis (Table S2) neither blood loss 500-1,000 or $>1,000 \mathrm{~mL}$ were identified as being associated with inferior long-term survival $(\mathrm{P}=0.646$ and $\mathrm{P}=0.123$, respectively).
This analysis identified that the same patient factors (except preoperative creatinine clearance) are independently associated with inferior long-term survival following AVR as for CABG. There was reduced 12-hour blood loss following AVR likely relating to the antiplatelet medication in the CABG population.

\section{Discussion}

In this large study of 6,265 patients, we have been able to demonstrate that significant 12 -hour blood loss is associated with inferior long-term survival following CABG. By imposing 30-day conditional survival we were able to examine the effect of bleeding on long-term survival, excluding those patients who experienced significant early complications_-including bleeding, but succumbed during the early post-operative period. As a result, we have a large population of patients who survived 30 days and therefore in whom bleeding and other complications did not result in early mortality.

It is notable in this analysis that re-exploration for mediastinal bleeding and units of blood transfusion were not found to be independently associated with long-term survival in this cohort of patients with 30-day conditional survival. That is despite studies which demonstrate both of the these to be significantly associated with early postoperative mortality.

In terms of re-exploration for bleeding, studies have demonstrated that return to theatre is associated with a 2-4-fold increase in postoperative mortality, but also a significant increase in postoperative complications, including stroke, renal failure, prolonged ventilation, sternal wound infection, pulmonary complications and gastrointestinal complications $(4,8-10,12-14)$. It is notable that several of these studies have observed that outcomes are superior for patients who are re-explored early following surgery, suggesting that delayed re-exploration is detrimental-perhaps (12-14). This may be related to the on-going blood-loss that occurs in these patients, associated with haemodynamic compromise and increased blood transfusion. The lack of association when considering long term outcomes in this study likely relates to exclusion of those who suffer mortality within 30 days-likely to be the more severe cases.

Regarding blood transfusion, there are a series of studies demonstrating the detrimental impact on postoperative outcomes $(3,7)$. For example, Koch et al. identified 
A

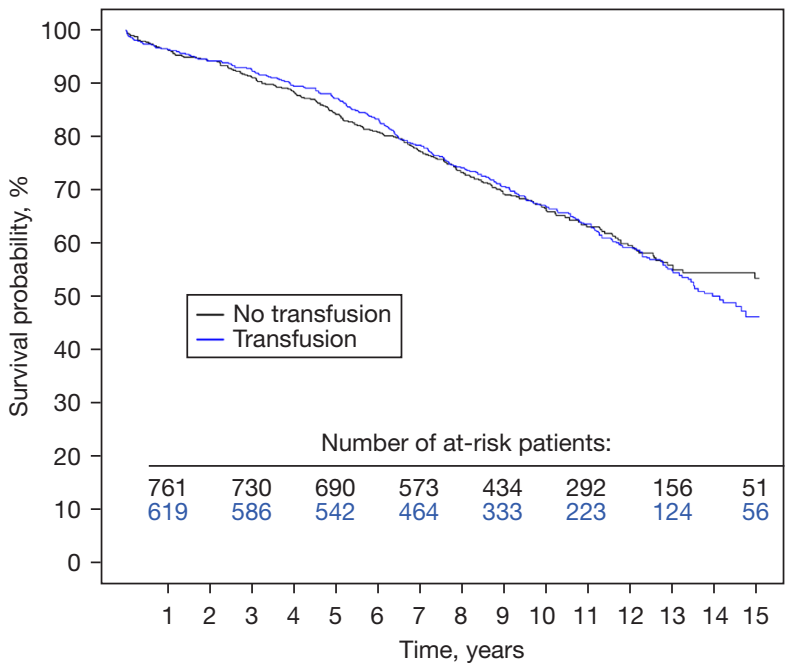

B

Survival of patients in the $>1,000 \mathrm{~mL}$ bleeding group

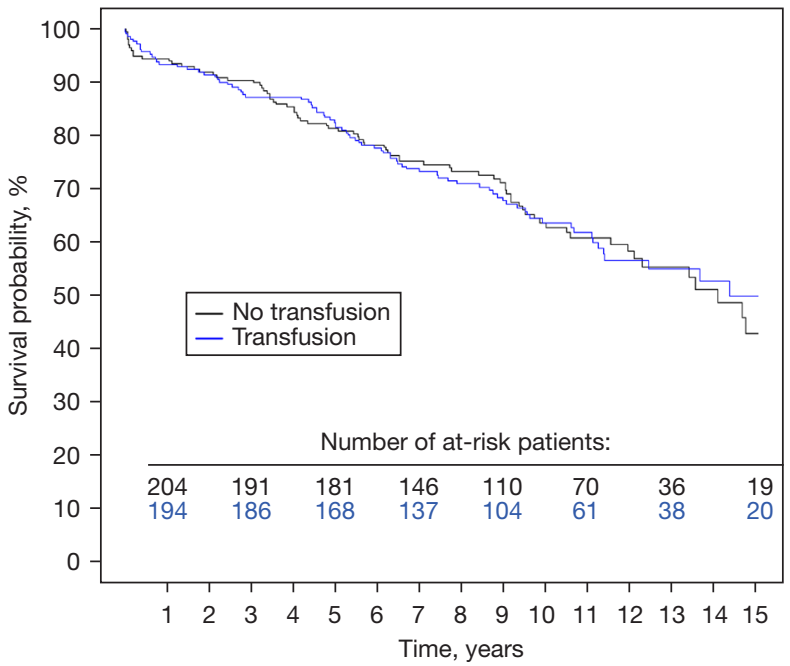

Figure 3 Impact of receiving blood transfusion on long-term survival for patients with $>500$ or $>1,000 \mathrm{~mL} \mathrm{12-hour} \mathrm{blood} \mathrm{loss.}$

perioperative blood transfusion as the single most reliable factor associated with postoperative morbidity (6). They described an increase in mortality (OR, 1.77; $95 \%$ CI, 1.67-1.87; $\mathrm{P}<0.0001)$, renal failure (OR, 2.06; $95 \%$ CI, 1.87-2.27; $\mathrm{P}<0.0001)$, prolonged ventilator support (OR, 1.79; 95\% CI, 1.72-1.86; $\mathrm{P}<0.0001$ ), severe infection (OR, 1.76; 95\% CI, 1.47-1.63; $\mathrm{P}<0.0001$ ), cardiac complications (OR, 1.76; 95\% CI, 1.47-1.63; $\mathrm{P}<0.0001)$, and neurologic events (OR, 1.37; 95\% CI, 1.30-1.44; $\mathrm{P}<0.0001)$. Of note, in a different analysis, they also observed that there was an association between transfusion and late survival following CABG (6). Why blood transfusion should have an impact on long-term survival is not clear, but it has been suggested that this may relate to immunomodulatory effects of blood transfusion that are thought to persist for many months (15). A more recent study has sought to examine this potential long-term impact of transfusion following CABG and initially made a similar observation of a longterm survival impact (16). It is worth also highlighting that there is now a trend towards 'restrictive' rather than 'liberal' transfusion following cardiac surgery and a recent metaanalysis concluded that early outcomes are not negatively impacted by restrictive transfusion (17). Longer term outcomes are not really addressed in that study, but it will be interesting to hypothesise that these may be improved with the restrictive protocols, at least for the CABG population. Unfortunately, discharge $\mathrm{Hb}$ was not available for our patients, but it would have been interesting to see if this correlated with long-term outcome.

Our data agree that for patients who are re-explored or receive blood transfusion, if they survive to 30 days their long-term outcomes are unaffected by this early insult. This implies that once patients recover there are no longterm impacts of having been re-explored or receiving blood transfusion, and that the negative effects of these are both focused in the early post-operative period. This is not the case for bleeding though, which does appear to have an impact. This then, raises a further question: why does significant bleeding have an adverse influence on long-term survival? It is recognised that 12 -hour blood loss is associated with increased incidence of complications including stroke, renal failure and low cardiac output, that contribute to the increased early mortality (18). However, these can also be a contributing factor to the long-term survival impact we have observed-since non-fatal sequelae of these complications could certainly account for increased long-term morbidity. Furthermore, it is well recognised that peri-operative anaemia is associated with inferior longterm outcomes and it may be that a persistent anaemia, if untreated, may contribute to the inferior long-term survival (19). As such elective patients at our centre with pre-operative anaemia are reviewed by a haematologist for pre-operative optimisation.

It is notable that the association between blood loss and inferior long-term survival was not seen in our patients undergoing isolated AVR. These patients had significantly lower 
levels of cardiovascular comorbidity-for example, incidence of smoking was $17.3 \%$ lower, hypertension $22.2 \%$ lower and diabetes was $60 \%$ less prevalent. Patients undergoing CABG would therefore be more likely to suffer from a generalised vasculopathy that perhaps would render them more susceptible to the blood-loss and consequent anaemia.

It was also observed in our study that re-exploration and blood transfusion were not strongly associated with 12-hour blood loss in our series, which is interesting since it would be predicted that those experiencing significant bleeding would be more likely to be re-explored and/or receive blood transfusion. Regarding re-exploration, this may reflect that the threshold to return a patient to theatre varies between consultant surgeons, with some preferring to re-explore patients early when it is apparent, they may be bleeding-before they have experienced significant blood-loss. In terms of blood-transfusion, this lack of association with bleeding may reflect acceptance of a range of preoperative $\mathrm{Hb}$ levels during this period. For example, $36.5 \%$ of patients in the $<500 \mathrm{~mL}$ bleeding group had a preoperative $\mathrm{Hb}$ of $<120 \mathrm{~g} / \mathrm{dL}$ and were anaemic. As such, it is likely that many of these patients would have received blood transfusion as a consequence of haemodilution during $\mathrm{CPB}$ and intraoperative blood loss. Therefore, the extent of blood transfusion may not necessarily reflect bleeding in this patient cohort. It is now recognised that preoperative anaemia is an independent predictor of inferior outcome following cardiac surgery $(20,21)$. As such there are now efforts to treat anaemia preoperatively, with evidence that this improves outcomes (22).

Our multivariable analysis also identified other factors that are associated with inferior long-term survival following CABG: age, smoking history, raised BMI, CPD, diabetes, impaired preoperative renal function, impaired left ventricular function and low preoperative $\mathrm{Hb}$ level. These factors are concordant with those identified by other studies examining long-term outcomes following CABG $(23,24)$. In addition, some studies identify use of arterial grafts to be associated with improved long-term survival (25). At our centre over this period the use of arterial grafts was comparatively low and as such our study was not powered to examine this.

Identifying that postoperative bleeding can have a negative impact on long-term survival emphasises the importance of intraoperative haemostasis and taking steps to minimise postoperative bleeding. Some centres, including ours, have introduced a haemostasis checklist which is designed to reduce post-operative bleeding complications $(1,26)$. Introduction of this simple checklist at our centre has been associated with a significant reduction in mean 12 -hour blood loss and an associated $42 \%$ reduction in re-exploration rate, and a substantial saving on the use of blood products (1). In addition to these early benefits, it can be appreciated that this intervention will also be associated with improved longer-term survival. In this study we also performed a propensity matched analysis which demonstrated a more than double 30-day mortality in patients who experience significant port-operative bleeding highlighting the impact of bleeding on early outcomes.

\section{Limitations}

This is a single centre retrospective study which has inherent limitations including the inability to demonstrate causality. In order to examine long-term outcomes our patient cohort underwent surgery from 2003-2013. We acknowledge that some practices during this period may not reflect contemporary practice and this must be considered when thinking about the generalisability of the results-however this enables us to consider long term outcomes. Unfortunately, we could not retrieve detailed information on preoperative antiplatelet and other anticoagulant medications as these may have had an impact on bleeding outcomes and as such we could not risk adjust for this-furthermore, the nature of the perioperative antiplatelet treatment has evolved with newer medications now available. Similarly, we did not have information on preoperative coagulation screens or renal function (other than those who were dialysis dependent) which could also influence postoperative bleeding. Additionally, factors such as hepatic cirrhosis and tricuspid valve regurgitation may also impact coagulation status and are variables that we have been unable to account for. We could also not access coagulation screen results. We have also not been able to retrieve cause of death during follow-up in order to understand potential links between bleeding and inferior survival. Furthermore, we do not have data on myocardial viability, perioperative myocardial infarction or the presence of ischaemic mitral regurgitationall of which may also impact on early and late outcomes following surgery. In this study we have focused on patients with 30-day conditional survival and as such this will limit the generalisability of the findings. Despite these limitations we have a large cohort of patients from a single centre providing sufficient data to perform robust statistical analyses. 


\section{Conclusions}

With a large dataset and long-term follow-up, we have been able to demonstrate that 12-hour postoperative blood loss volume is an independent predictor of long-term survival in patients undergoing CABG. It has been long recognised that bleeding impacts on early outcomes, but less focus has been placed on longer term outcomes. Having an insight into the longer-term impact of bleeding, further emphasises the importance of intra-operative haemostasis, and strategies aimed to minimise post-operative bleeding.

\section{Acknowledgments}

Funding: None.

\section{Footnote}

Reporting Checklist: The authors have completed the STROBE reporting checklist. Available at https://dx.doi. org/10.21037/jtd-21-1241

Data Sharing Statement: Available at https://dx.doi. org/10.21037/jtd-21-1241

Peer Review File: Available at https://dx.doi.org/10.21037/ jtd-21-1241

Conflicts of Interest: All authors have completed the ICMJE uniform disclosure form (available at https://dx.doi. org/10.21037/jtd-21-1241). Jason M. Ali serves as an unpaid editorial board member of Fournal of Thoracic Disease. The other authors have no other conflicts of interest to declare.

Ethical Statement: The authors are accountable for all aspects of the work in ensuring that questions related to the accuracy or integrity of any part of the work are appropriately investigated and resolved. The study was conducted in accordance with the Declaration of Helsinki (as revised in 2013). The study was approved by the Royal Papworth Hospital Clinical Governance Department and individual consent for this retrospective analysis was waived.

Open Access Statement: This is an Open Access article distributed in accordance with the Creative Commons Attribution-NonCommercial-NoDerivs 4.0 International License (CC BY-NC-ND 4.0), which permits the noncommercial replication and distribution of the article with the strict proviso that no changes or edits are made and the original work is properly cited (including links to both the formal publication through the relevant DOI and the license). See: https://creativecommons.org/licenses/by-nc-nd/4.0/.

\section{References}

1. Ali JM, Gerrard C, Clayton J, et al. Reduced re-exploration and blood product transfusion after the introduction of the Papworth haemostasis checklist†. Eur J Cardiothorac Surg 2019;55:729-36.

2. Pearse BL, Smith I, Faulke D, et al. Protocol guided bleeding management improves cardiac surgery patient outcomes. Vox Sang 2015;109:267-79.

3. Velasquez CA, Singh M, Bin Mahmood SU, et al. The Effect of Blood Transfusion on Outcomes in Aortic Surgery. Int J Angiol 2017;26:135-42.

4. Vivacqua A, Koch CG, Yousuf AM, et al. Morbidity of bleeding after cardiac surgery: is it blood transfusion, reoperation for bleeding, or both? Ann Thorac Surg 2011;91:1780-90.

5. Ali JM, Wallwork K, Moorjani N. Do patients who require re-exploration for bleeding have inferior outcomes following cardiac surgery? Interact Cardiovasc Thorac Surg 2019;28:613-8.

6. Koch CG, Li L, Duncan AI, et al. Morbidity and mortality risk associated with red blood cell and blood-component transfusion in isolated coronary artery bypass grafting. Crit Care Med 2006;34:1608-16.

7. Yu PJ, Cassiere HA, Dellis SL, et al. Dose-dependent effects of intraoperative low volume red blood cell transfusions on postoperative outcomes in cardiac surgery patients. J Cardiothorac Vasc Anesth 2014;28:1545-9.

8. Ohmes LB, Di Franco A, Guy TS, et al. Incidence, risk factors, and prognostic impact of re-exploration for bleeding after cardiac surgery: A retrospective cohort study. Int J Surg 2017;48:166-73.

9. Fröjd V, Jeppsson A. Reexploration for Bleeding and Its Association With Mortality After Cardiac Surgery. Ann Thorac Surg 2016;102:109-17.

10. Ruel M, Chan V, Boodhwani M, et al. How detrimental is reexploration for bleeding after cardiac surgery? J Thorac Cardiovasc Surg 2017;154:927-35.

11. Biancari F, Kinnunen EM, Kiviniemi T, et al. Metaanalysis of the Sources of Bleeding after Adult Cardiac Surgery. J Cardiothorac Vasc Anesth 2018;32:1618-24. 12. Biancari F, Mikkola R, Heikkinen J, et al. Estimating the 
risk of complications related to re-exploration for bleeding after adult cardiac surgery: a systematic review and metaanalysis. Eur J Cardiothorac Surg 2012;41:50-5.

13. Kristensen KL, Rauer LJ, Mortensen PE, et al. Reoperation for bleeding in cardiac surgery. Interact Cardiovasc Thorac Surg 2012;14:709-13.

14. Haneya A, Diez C, Kolat P, et al. Re-exploration for bleeding or tamponade after cardiac surgery: impact of timing and indication on outcome. Thorac Cardiovasc Surg 2015;63:51-7.

15. Blajchman MA. Immunomodulation and blood transfusion. Am J Ther 2002;9:389-95.

16. Tran L, Greiff G, Pleym H, et al. Transfusion of red blood cells in coronary surgery: is there an effect on long-term mortality when adjusting for risk factors and postoperative complications? Eur J Cardiothorac Surg 2018;53:1068-74.

17. Shehata N, Mistry N, da Costa BR, et al. Restrictive compared with liberal red cell transfusion strategies in cardiac surgery: a meta-analysis. Eur Heart J 2019;40:1081-8.

18. Kinnunen EM, Juvonen T, Airaksinen KE, et al. Clinical significance and determinants of the universal definition of perioperative bleeding classification in patients undergoing coronary artery bypass surgery. J Thorac Cardiovasc Surg 2014;148:1640-1646.e2.

19. Butcher A, Richards T. Cornerstones of patient blood management in surgery. Transfus Med 2018;28:150-7.

20. Ogami T, Matsue Y, Kawasumi R, et al. Prognostic

Cite this article as: Senage T, Gerrard C, Moorjani N, Jenkins DP, Ali JM. Early postoperative bleeding impacts longterm survival following first-time on-pump coronary artery bypass grafting. J Thorac Dis 2021;13(10):5670-5682. doi: $10.21037 /$ jtd-21-1241 implications of preoperative chronic kidney disease and anemia in patients undergoing coronary artery bypass graft surgery. Surg Today 2017;47:245-51.

21. Padmanabhan H, Brookes MJ, Nevill AM, et al. Association Between Anemia and Blood Transfusion With Long-term Mortality After Cardiac Surgery. Ann Thorac Surg 2019;108:687-92.

22. Spahn DR, Schoenrath F, Spahn GH, et al. Effect of ultrashort-term treatment of patients with iron deficiency or anaemia undergoing cardiac surgery: a prospective randomised trial. Lancet 2019;393:2201-12.

23. Pu A, Ding L, Shin J, et al. Long-term Outcomes of Multiple Arterial Coronary Artery Bypass Grafting: A Population-Based Study of Patients in British Columbia, Canada. JAMA Cardiol 2017;2:1187-96.

24. Galbut DL, Kurlansky PA, Traad EA, et al. Bilateral internal thoracic artery grafting improves long-term survival in patients with reduced ejection fraction: a propensity-matched study with 30-year follow-up. J Thorac Cardiovasc Surg 2012;143:844-853.e4.

25. Taggart DP. Current status of arterial grafts for coronary artery bypass grafting. Ann Cardiothorac Surg 2013;2:427-30.

26. Loor G, Vivacqua A, Sabik JF 3rd, et al. Process improvement in cardiac surgery: development and implementation of a reoperation for bleeding checklist. J Thorac Cardiovasc Surg 2013;146:1028-32. 
Survival according to the $\mathbf{1 2}$ hours blood loss

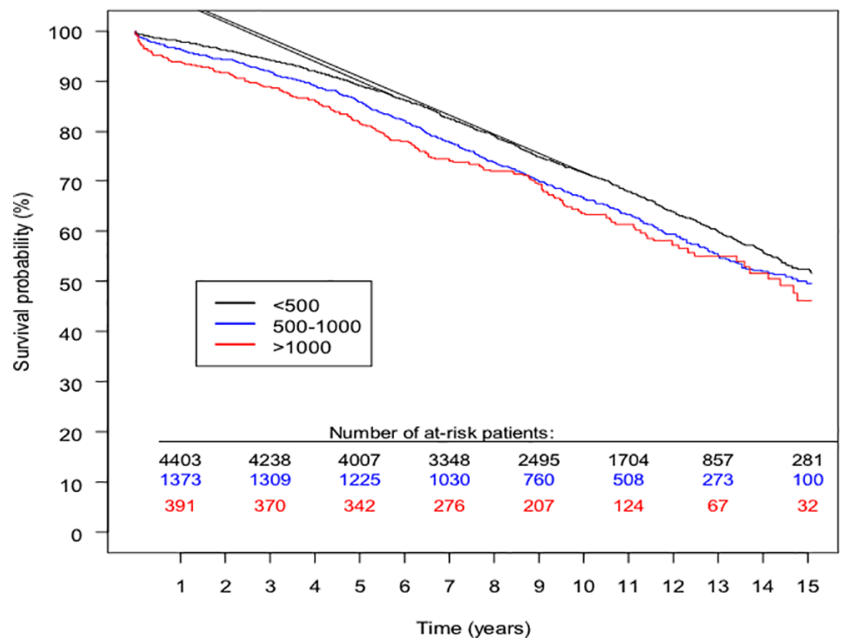

Figure S1 Impact of bleeding on long-term survival including all patients. 
Table S1 Correlates of long-term survival: univariate analysis

\begin{tabular}{|c|c|c|c|}
\hline Clinical data & Patients, $n=3,689$ & $\mathrm{HR}$ & $P$ value \\
\hline Before 5 years post-surgery & & 1.015 & 0.864 \\
\hline After 5 years post-surgery & & 1.453 & $<0.001$ \\
\hline Age, years $($ ref <60) & $67.3 \pm 12.9$ [16-95] & & \\
\hline 60-70 y old, n (\%) & $917(24.9)$ & 1.500 & $<0.001$ \\
\hline 70-80 y old, n (\%) & $1,310(35.5)$ & 3.347 & $<0.001$ \\
\hline >80 y old, n (\%) & $574(15.6)$ & 5.312 & $<0.001$ \\
\hline Smoker, n (\%) & $1,792(54.6)$ & 1.347 & $<0.001$ \\
\hline BMI, m² (ref =20-25) & $27.0 \pm 5.2[15.1-79.6]$ & & \\
\hline$<20, \mathrm{n}(\%)$ & $183(5.1)$ & 1.638 & $<0.001$ \\
\hline 20-25, n (\%) & $1,172(32.4)$ & - & - \\
\hline 25-30, n (\%) & $1,440(39.8)$ & 1.012 & 0.863 \\
\hline $30-40, \mathrm{n}(\%)$ & $743(20.6)$ & 1.159 & 0.071 \\
\hline$>40, \mathrm{n}(\%)$ & $76(2.1)$ & 1.410 & 0.070 \\
\hline \multicolumn{4}{|l|}{$\mathrm{CPD}(\mathrm{ref}=\mathrm{none})$} \\
\hline No pulmonary disease, $\mathrm{n}(\%)$ & $3,156(86.2)$ & - & - \\
\hline Oral therapy, n (\%) & $256(6.9)$ & 2.035 & $<0.001$ \\
\hline Insulin, n (\%) & $78(2.1)$ & 1.736 & 0.001 \\
\hline Creatinine clearance, $\mathrm{mL} / \mathrm{min}(\mathrm{ref}>60)$ & $71.2 \pm 28.6[17-269]$ & & \\
\hline$<30, \mathrm{n}(\%)$ & $133(3.8)$ & 2.575 & $<0.001$ \\
\hline $30-60$, n (\%) & $1,222(34.6)$ & 1.908 & $<0.001$ \\
\hline$>60, \mathrm{n}(\%)$ & $2,177(61.6)$ & - & - \\
\hline \multicolumn{4}{|l|}{ Left ventricular function $($ ref $=$ good $)$} \\
\hline Good LV, n (\%) & $2,420(68.6)$ & - & - \\
\hline Moderate LV, n (\%) & $900(25.5)$ & 1.288 & $<0.001$ \\
\hline Poor LV, n (\%) & $207(5.9)$ & 1.278 & 0.034 \\
\hline
\end{tabular}

Table S1 (continued) 
Table S1 (continued)

\begin{tabular}{|c|c|c|c|}
\hline Clinical data & Patients, $n=3,689$ & $\mathrm{HR}$ & $P$ value \\
\hline Elective, n (\%) & $3,293(89.3)$ & 0.663 & $<0.001$ \\
\hline Urgent, n (\%) & $370(10.0)$ & - & - \\
\hline Emergency, n (\%) & $25(0.7)$ & - & - \\
\hline Preoperative $\mathrm{Hb}($ ref $>120)$ & $121 \pm 16[80-179]$ & & \\
\hline $80-100, n(\%)$ & $350(9.5)$ & 2.603 & $<0.001$ \\
\hline $100-120, \mathrm{n}(\%)$ & $1,265(34.3)$ & 1.904 & $<0.001$ \\
\hline$>120, \mathrm{n}(\%)$ & $2,073(56.2)$ & - & - \\
\hline Cross clamp time, min & $17 \pm 28[13-253]$ & 0.999 & 0.521 \\
\hline Return to theatre, $\mathrm{n}(\%)$ & $209(5.7)$ & 1.028 & 0.820 \\
\hline \multicolumn{4}{|c|}{ Blood loss in the first 12 hours (ref $<500$ ) } \\
\hline$<500 \mathrm{~mL}, \mathrm{n}(\%)$ & $2,858(77.7)$ & - & - \\
\hline 500-1,000 mL, n (\%) & $581(15.8)$ & 1.203 & $<0.001$ \\
\hline$>1,000 \mathrm{~mL}, \mathrm{n}(\%)$ & $240(6.5)$ & 1.515 & $<0.001$ \\
\hline \multicolumn{4}{|c|}{ Blood transfusion (red cells) (ref = none) } \\
\hline None, n (\%) & $1,893(51.3)$ & - & - \\
\hline
\end{tabular}

BSA, body surface area; BMI, body mass index; CPD, chronic pulmonary disease; COPD, chronic obstructive pulmonary disease; LV, left ventricle; Hb, haemoglobin; $\mathrm{CPB}$, cardiopulmonary bypass. 
Table S2 Multivariable Cox model analysis of long-term survival

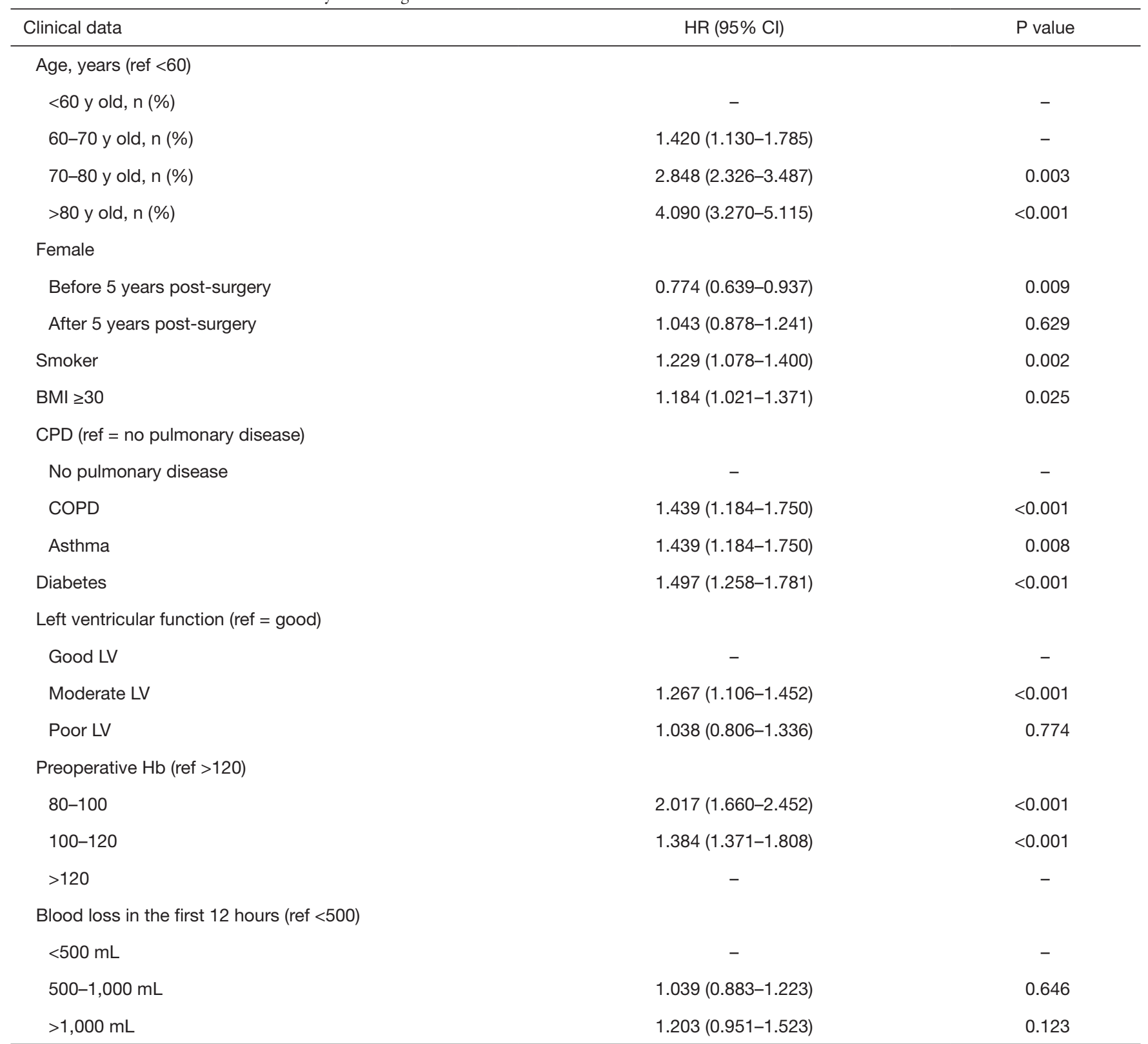

$\mathrm{Cl}$, confidence interval; BMI, body mass index; CPD, chronic pulmonary disease; COPD, chronic obstructive pulmonary disease; LV, left ventricle; $\mathrm{Hb}$, haemoglobin. 